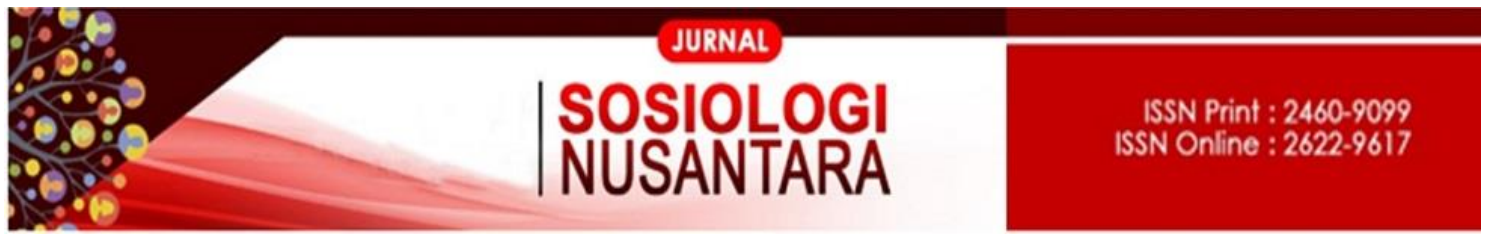

https://ejournal.unib.ac.id/index.php/jsn

DOI ://doi.org/10.33369/jsn.4.1.10-19

\title{
DISFUNGSI KELUARGA DALAM PENDIDIKAN FORMAL ANAK \\ (Studi Kasus Desa Durian Mas Kecamatan Kota Padang, Kabupaten Rejang Lebong, Bengkulu)
}

\section{FAMILY DISFUNCTION IN FORMAL EDUCATION OF CHILDREN (Case Study Durian Mas Village, Sub-District of Padang, Rejang Lebong District, Bengkulu)}

\author{
Rahmawati Talopo', Hasan Pribadi' ${ }^{2}$, Asep Topan ${ }^{3}$ \\ rahmatalopo@gmail.com \\ 123. Fakultas Ilmu Sosial dan Ilmu Politik, Universitas Bengkulu
}

\begin{abstract}
Abstrak
Penelitian ini bertujuan untuk mengetahui dan mendeskripsikan disfungsi keluarga pada pendidikan formal anak. Metode yang digunakan dalam penelitian ini adalah metode kualitatif deskriptif. Subyek penelitian adalah para orang tua yang memiliki anak usia sekolah kelas 2,3, dan 4 Sekolah Dasar dengan umur berkisar 8-10 tahun. Informan penelitian berdasarkan sumber data yang dimintai informasinya sesuai dengan masalah penelitian. Data dianalisis secara kualitatif melalui proses reduksi data, penyajian data, dan penarikan kesimpulan. Penelitian menghasilkan kesimpulan yakni penyebab terjadinya disfungsi keluarga sebagai kelompok sosial di mana terjadi kekacauan peran dan fungsi antar anggota keluarga yaitu pada pendidikan formal anak dikarenakan kesibukan orang tua dalam bekerja, kurangnya pengetahuan orang tua tentang pendidikan, dan rendahnya pendidikan orang tua. Sehingga anak menjadi malas, ketinggalan pelajaran di sekolah dan sering tidak naik kelas.
\end{abstract}

Kata Kunci : Disfungsi, Keluarga, dan Pendidikan

\begin{abstract}
This study aims to identify and describe the family dysfunction in the formal education of children. The method used in this research is descriptive qualitative method. Subjects were parents who have school age children classes 2,3, and 4 elementary schools with ages ranging from 8-10 years. The informant research based on source data that the information held according to research problem. Data were analyzed qualitatively through the process of data reduction, data presentation, and conclusion. The research lead to the conclusion that the cause of the dysfunction of the family as a social group in which there was chaos roles and functions among family members is the formal education of children due to busy parents in work, lack of parental knowledge about
\end{abstract}


education, and lack of education of parents. So that children become lazy, missed lessons at school and often do not grade.

Keywords : Disfunction, Family, and Education

\section{PENDAHULUAN}

Dalam sistem pendidikan terdapat berbagai komponen atau bagian yang memiliki peran dan fungsi masing-masing, tiap-tiap bagian dikatakan sebagai satuan pendidikan. Satuan pendidikan adalah kelompok layanan pendidikan yang menyelenggarakan pendidikan pada jalur formal yang pada umumnya diselenggarakan oleh institusi yang disebut sekolah, dan memiliki jenjang pendidikan yang terstruktur, yaitu SD, SMP, SMA, dan Perguruan Tinggi. Informal merupakan jalur yang bersifat mandiri yang dilakukan oleh keluarga ataupun lingkungan, disini pendidikan ini dapat dilakukan dimanapun, kapanpun, dan dengan siapapun yaitu pada bimbingan keluarga atau lingkungananak non formal merupakan jalur pendidikan yang berada diluar pendidikan formal, yang dapat dilakukan secara berjenjang dan terstruktur yaitu pada bimbingan belajar atau kursus keterampilan (UU Sistem Pendidikan Nasional,2003).

Pusat pendidikan yang pertama adalah lingkungan keluarga, pendidikan di lingkungan keluarga sangat strategis untuk memberikan pendidikan ke arah kecerdasan, budi pekerti atau kepribadian serta persiapan hidup di masyarakat. Orang tua akan menjadi contoh bagi anak, anak biasanya akan menirukan apa saja yang dilakukan oleh orang tua. Kedua orangtua didalam sebuah keluarga berkewajiban membantu, menolong, membimbing dan mengarahkan anak-anak yang belum dewasa di lingkungannya dalam pertumbuhan dan perkembangan mencapai kedewasaan masingmasing. Di dalam kegiatan orang tua mendidik anak-anaknya, secara implisit tersirat usaha memenuhi kebutuhan untuk memberikan bekal kepada anak-anak agar memperoleh kehidupan yang layak dan bersifat manusiawi setelah mencapai kedewasaannya kelak (Nawawi, 1985:9)

Dukungan orang tua sangat penting dalam mewujudkan keberhasilan pendidikan anak. Namun, masih banyak orang tua yang kurang menyadari akan perannya dalam mendukung pendidikan anak dan menyerahkan sepenuhnya pada sekolah. Seperti yang terjadi di SDN 68 Desa Durian Mas. Sikap orang tua yang tidak 
menyadari perannya dalam mendukung pendidikan anak sangat mempengaruhi keberhasilan anak dalam belajar dan bersosialisasi. Sehingga banyak yang menyerahkan pendidikan anak sepenuhnya kepada pihak sekolah. Para orang tua tidak segan mendatangi guru untuk marah bahkan memaksa guru untuk menaikkan anaknya pada saat pembagian raport. Bahkan mereka tidak mau tahu walaupun daftar nilai anak selama proses belajar telah di berikan mereka tetap memaksakan agar anak di naikkan.

Padahal untuk mewujudkan keberhasilan pendidikan dibutuhkan kerjasama antara pihak sekolah dan orang tua. Pentingnya peran orang tua terhadap pendidikan anak bukanlah hal yang sepele karena pendidikan adalah modal utama yang harus dimiliki oleh setiap individu yang hidup agar dapat bertahan menghadapi perkembangan zaman (Ariyani,2016). Adanya dukungan dari orang tua dalam pendidikan anak-anak memberikan dampak positif bagi anak. Banyak yang mencapai kesuksesan setelah mereka menginjak usia dewasa dan terjun ke dalam dunia sosial yang sebenarnya.

Fokus masalah dalam penelitian ini adalah mendeskripsikan tentang penyebab dari terjadinya disfungsi keluarga dalam pendidikan formal anak. Tujuan dari penelitian ini yaitu untuk mengetahui penyebab terjadinya disfungsi peran orang tua dalam pendidikan anak. Penelitian ini menggunakan teori fungsional struktural. Menurut teori fungsional sturuktural masyarakat merupakan suatu sistem sosial yang terdiri atas bagian bagian atau elemen yang salaing berkaitan dan saling menyatu dalam keseimbangan.

\section{METODE PENELITIAN}

Penelitian ini menggunakan metode penelitian kualitatif dan dilakukan di Desa Durianmas Kecamatan Kotapadang Kabupaten Rejang Lebong Provinsi Bengkulu. Penelitian dilakukan di desa Durianmas karena di lokasi ini masih banyak orang tua yang tidak menjalankan fungsinya dalam bidang pendidikan anak maka peneliti menjadikan wilayah tersebut sebagai lokasi penelitian. Metode pengumpulan data yang digunakan dalam penelitian ini yakni dengan menggunakan metode observasi, wawancara, dan dokumentasi. Penentuan informan dalam penelitian ini dilakukan dengan menggunakan teknik Snowball Sampling. Teknik analisis data yang digunakan yakni reduksi data, penyajian data, serta penarikan kesimpulan. 


\section{PEMBAHASAN}

\section{Kesibukan Orang Tua Dalam Bekerja}

Keluarga merupakan benih akal menyusun kematangan individu dan struktur kepribadian. Anak-anak mengikuti orang tua berbagai kebiasaan dan perilaku dengan demikian keluarga adalah elemen pendidikan lain yang palingnya, tepat dan amat besar. Keluarga adalah salah satu elemen pokok pembangunan entitas-entitas pendidikan, menciptakan proses naturalisasi sosial membentuk kepribadian-kepribadian serta memberi berbagai kebiasaan baik pada anak.

Setiap harinya ibu NA sibuk bekerja di sawah milik mereka, ketika pulang hari sudah sore. Pada malam harinya setelah makan malam mereka berkumpul nonton bersama. Anak ibu NA juga dibiarkan nonton hingga larut malam. Anak selalu diberi kebebasan untuk memilih apakah anak akan belajar atau tidak, baik pada pada malam hari maupun pada siang hari saat sepulang dari sekolah. Orang tua yang bekerja dari pagi hingga sore menjadikan alasan orang tua tidak mengajarkan anaknya pada malam hari dirumah. Bahkan saat musim panen ibu NA tidak melarang anaknya yang masih bersekolah untuk ikut membantu panen padi disawah bahkan juga membantu tetangga untuk upahan mengangkut padi dari sawah.

Sedangkan keluarga dari ibu IL (39 tahun), memiliki 1 orang anak yang masih bersekolah di sekolah dasar, pendidikan terakhir ibu IL yaitu SD dan suami ibu IL tamatan SMP. Pendidikan yang minim dan pekerjaan sebagai penjual sayur di pasar serta suami yang bekerja sebagi petani kopi, membuat mereka jarang di rumah dan memperhatikan anak-anaknya. Ibu IL bekerja menjual sayuran keliling setiap pagi, berangkat kira-kira pukul 11.00 malam ke kota Lubuk Linggau untuk membeli sayuran yang akan dijual pada esok hari. Ibu IL kembali ke rumah menjelang subuh dan harus menyiapkan sayuran yang akan di jual. Pagi hari dari jam 08.00 pagi ibu IL akan berkeliling dari desa ke desa menjual sayuran dan kembali ke rumah pada pukul 13.00. Dengan kesibukan setiap harinya Ibu IL jarang sekali mengajarkan anaknya belajar 
seperti membaca ataupun menulis dirumah. Suami ibu IL juga demikian, ia tidak memperdulikan bagaimana perkembangan anaknya.

Pendidikan yang rendah membuat ibu IL dan suami hanya menyerahkan pendidikan anaknya sepenuhnya kepada pihak sekolah saja. Motivasi belajar dari ibu IL kepada anaknya juga sangat kurang. Pada malam hari ataupun sepulang sekolah anakanaknya diberi kebebasan untuk bermain ataupun belajar, apa yang mereka inginkan terserah pada anaknya saja. Sedangkan ibu IL pada malam hari berisirahat untuk kembali berjualan pada esok harinya sehingga waktu untuk mengontrol belajar anak pun tidak ada. Setiap paginya saat anak berangkat sekolah ibu IL sudah lebih dulu berangkat mengambil bahan berjualan sayur, saat pulang untuk bersiap jualan anaknya sudah berangkat dan saat pulang berjualan anak bu IL juga sudah pergi bermain bersama teman di dekat rumahnya hingga sore. Malam harinya dihabiskan untuk nonton televisi dan begitu setiap harinya. Sehingga perkembangan belajar anak di sekolah tidak di ketahui, yang ibu IL tahu hanya hasil ketika pembagian raport.

\section{Kurangnya Pengetahuan OrangTua Tentang Pendidikan}

Keluarga merupakan lingkunganyang pertama memberikan pendidikan terhadap anak. Orang tua seharusnya memahami bahwa merekalah sebagai penanggung jawab utama dalam pendidikan putra-putrinya. Secara umum, berhasil tidaknya pendidikan seorang anak, biasanya dihubungkan dengan perkembangan pribadi orang tuanya dan baik tidaknya hubungan, komunikasi dan cara pembelajaran atau pendidikan dalam keluarga.

Salah satu orang tua siswa, yaitu ibu dari HS menyatakan bahwa mereka jarang sekali menyuruh anaknya untuk belajar. Hal tersebut dikarenakan peran orang tua dalam hal mendidik tidak ditegaskan kepada anak-anaknya. Anggapan mereka bahwa peran orang tua hanyalah peran sebagai pencari nafkah, dimana peran orang tua adalah dalam memenuhi kebutuhan dasar anak yaitu kebutuhan pangan, sandang dan papan. Dan ketika anak memasuki usia sekolah urusan belajar anak di serahkan sepenuhnya kepada sekolah, dan anak itu sendiri apakah nantinya akan tetap sekolah atau ingin berhenti sekolah semua diserahkan kepada anak.

Pada kasus orang tua ini, ia hanya berfikir jika tidak perlu sekolah yang pintar jika hanya ingin mencari uang, dengan berkebun juga cukup untuk mendapatkan uang 
untuk memenuhi kebutuhan sehari-hari. Sehingga orang tua akan lebih senang jika anak membantu mereka di kebun daripada anak belajar disekolah.

Peran orang tua yang telah memikirkan kebutuhan makan, pakaian serta tempat tinggal untuk anak-anak mereka juga merupakan suatu kewajiban dari orang tua. Namun, selain daripada itu untuk mencerdaskan anak, memberikan pengetahuan serta membentuk karakter yang lebih baik pada diri seorang anak, maka diperlukan sebuah pendidikan. Pendidikan yang layak merupakan faktor utama dalam membentuk sumber daya manusia yang berguna.

Perolehan pendidikan pada anak juga merupakan suatu peran orang tua ketika berada dirumah. Orangtua seharusnya mengawasi dan membantu anak ketika belajar atau mengerjakan pekerjaan rumah (PR), jarang terlihat di desa Durian Mas. Salah satu orang tua yaitu AK berfikir, jika anak sudah diberi pendidikan sekolah, maka yang berhak mengajarkan anak adalah guru-guru di sekolah. Sehingga dalam hal pendidikan, peran gurulah yang seharusnya lebih banyak dan bahkan sepenuhnya berperan dibandingkan orang tua. Orang tua hanya menyuruh anak sekolah, membelikan buku tulis, alat-alat tulis serta pemenuhan seragam sekolah.

Dalam kasus ini, orangtua menganggap pendidikan bukanlah tanggung jawab orang tua tetapi pendidikan merupakan tanggung jawab sekolah terutama guru yang mengajar di sekolah sehingga anak diserahkan sepenuhnya kepada pihak sekolah. Dan orang tua cenderung akan menyalahkan guru jika anak mereka tidak naik kelas.

\section{Rendahnya Tingkat Pendidikan Orang Tua}

Dengan demikian, latar belakang pendidikan orang tua, mempengaruhi segala kegiatan yang dilakukan di rumah dalam rangka membimbing belajar anak, dan usaha meningkatkan prestasi belajarnya. Para orang tua di desa Durian Mas mayoritas adalah pendidikan di tingkat Sekolah Dasar (SD) dan tingkat Sekolah Menengah Pertama (SMP) bahkan ada juga dari mereka yaang bahkan tidak tamat SD. Rendahnya pendidikan orang tua mempengaruhi pola pikir mereka terhadap untuk apa pentingnya pendidikan bagi mereka, sehingga anak-anak mereka pun tidak terlalu di dorong untukmendapatkanpendidikansetinggi-tingginya. Hanya sebagian kecil masyarakat yang menyekolahkan anak mereka ke tingkat perguruan tinggi. 
Selain permasalahan di atas, kendala Sumber Daya Manusia (SDM) orang tua menjadi penyebab kurangnya mereka dalam ikut serta meningkatkan prestasi anaknya. Banyak orang tua yang tidak mengenyam pendidikan tinggi, bahkan tidak sedikit mereka yang tidak bersekolah sama sekali. Hal ini lah yang menyebabkan mereka tidak menjalankan fungsi pendidikan pada anak, karena bagi mereka pendidikan yang mereka terima tidak ada bedanya antara mereka yang tamat SD dan tamat SMP sehingga tidak perlu sekolah tinggi jika nantinya akan bekerja menjadi petani seperti mereka juga.

\section{Analisis Teori Terhadap Disfungsi Keluarga Dalam Pendidikan Anak}

Pendidikan merupakan salah satu cara meningkatkan kualitas sumber daya manusia. Tanpa pendidikan ilmu pengetahuan dan kemajuan akan sulit untuk dicapai. Secara struktural terselenggaranya pendidikan yang ideal sesuai amanat UndangUndang Dasar 1945akan tercipta jika terjadi equilibrium (keseimbangan) antara subsistem-subsistem yang terstruktur dalam sebuah sistem pendidikan nasional. Subsistem dalam struktur yang mendukung terselenggaranya pendidikan, keluarga, serta masyarakat. Keseimbangan bisa terjadi jika setiap subsistem dalam struktur tersebut menjalankan fungsi dan perannya masing-masing dengan baik.

Sebagaimana asumsi dasar strukturalisme fungsional bahwa setiap struktur dalam sistem sosial, fungsional terhadap sistem yang lainya sebaliknya jika tidak fungsional maka struktur tersebut akan berpengaruh terhadap sistem yang lain. Berdasarkan hasil penelitian penyebab terjadinya disfungsi peran orang tua dalam pendidikan anak merupakan akibat dari ketidak fungsionalnya beberapa sistem yang ada dalam sruktur penyelenggara sistem pendidikan salah satunya yaitu lembaga keluarga khususnya orang tua.

\section{KESIMPULAN}

Disfungsi keluarga khususnya peran orang tua dalam pendidikan anak terjadi karena para orang tua di desa Durian Mas terlalu sibuk dalam bekerja sehingga tidak dapat mengawasi perkembangan belajar anak. Lalu kurangnya pengetahuan orang tua akan pentingnya pendidikan membuat mereka menyerahkan semua hal yang berkaitan dengan pendidikan kepada guru yang mengajar anak disekolah. Dan juga rendahnya pendidikan orang tua dapat mempengaruhi pola pikir mereka terhadap pendidikan, 
masyarakat desa Durian Masyang sebagian besar mempunyai pendidikan SD dan SMP bahkan ada juga yang tidak tamat SD membuat mereka berpikir bahwa pendidikan tidak begitu penting bagi mereka.

Kurangnya dukungan dari keluarga ini mengakibatkan anak menjadi tertinggal dalam pelajaran, bahkan anak sering tidak naik kelas. Tidak adanyadukungan dari orang tua dan orang tua hanya menyerahkan sepenuhnya kepada pihak sekolah karena bagi orang tua pendidikan bukan tanggung jawab mereka tetapi merupakan tanggung jawab sekolah sehingga orang tua tidak mengajarkan ketika anak berada di rumah karena mereka tidak memahami pentingnya pendidikan serta peran mereka dalam mengarahkan dan mengawasi pendidikan dalam memenuhi salah satu fungsi keluarga dalam bidang pendidikan.

Saran yang diberikan berdasarkan hasil penelitian yaitu (1) Dilihat dari tingkat pendidikan orang tua yang hanya tamat SD diharapkan pemikiran mereka tentang pendidikan lebih luas agar anak mereka dapat melanjutkan pendidikan ke jenjang yang lebih tinggi untuk masa depan yang lebih baik.(2) Peranan orang tua diharapkan untuklebih memperhatikan pendidikan anaknya dengan cara memberikan dorongan kepada siswa untuk terus belajar dan melanjutkan pendidikan yang lebih tinggi untuk keberhasilan pendidikan anak.

\section{DAFTAR PUSTAKA}

Abdullah. 2013. Sosiologi Pendidikan Individu, Masyarakat, dan Pendidikan. Jakarta: Rajawali Pers.

Ahmadi, Abu. 2002. Psikologi Sosial. Jakarta: Rineka Cipta.

Ahmadi, Abu. 2014. Sosiologi Pendidikan. Jakarta: Rineka Cipta.

Aliza, Kurniati. 2016. Makna Pendidikan Tinggi Bagi Keluarga Petani Kelapa Sawit. Skripsi. Bengkulu: Universitas Bengkulu.

Andriyani, Ika. 2010. Peran Serta Orang Tua Terhadap Kelangsungan Pendidikan Anak (Studi Kasus Pedagang Di Pasar Tersono Kecamatan Tersono Kabupaten Batang). Skripsi. Semarang: Geografi Universitas Negeri Semarang.

Arfiyatin, Alfi. 2013. "Disfungsi Keluarga". Jurnal Mahasiswa Unesa 1(3) Diakses 16 Juni, 2018. 
George, Ritzer. 2014. Sosiologi Ilmu Pengetahuan Berparadigma Ganda. Jakarta: Raja Grafindo Persada.

Hartono dan Arnicyn Aziz. 2001. Ilmu Sosial Dasar. Jakarta: Bumi Aksara.

Hardiyanti, Yati. 2011. Arti, Hakikat, Dan Dasar Pendidikan. Skripsi. Makasar: Universitas Hasanuddin.

Hasbullah. 2009. Dasar-dasar Ilmu Pendidikan. Jakarta: Rajawali Pers.

Ihsan, Puad. 2011. Dasar-Dasar Kependidikan. Jakarta: Rineka Cipta.

Khairuddin. 2002. Sosiologi Keluarga. Yogyakarta: Liberty.

Kristanti, Anastasia. 2015. Pengertian Pendidikan Menurut Ki Hajar Dewantara. http://anastasiakristanti.blogs.uny.ac.id (Diakses pada 3 Agustus 2018).

Lestari, Sri. 2012. Psikologi Keluarga: Penanaman Nilai dan Penanganan Konflik dalam Keluarga. Jakarta: Kencana.

Maryani, Deni. 2012. Upaya Ibu Sebagai Orangtua Tunggal Dalam Mendidik Anak Usia Dini. Skripsi. Bengkulu: Universitas Bengkulu.

Masitha, Dewi. 2016. "Makna Pendidikan Formal Bagi Orang Tua Siswa Di Pulau Poteran”. Jurnal Paradigma 4(1) Diakses 9 Maret, 2018.

Moeleong, J. Lexy. 2000. Metode Penelitian Kualitatif. Bandung: Remaja Rosda Karya.

Pusat Bahasa Departemen Pendidikan Nasional. 2008. Kamus Besar Bahasa Indonesia. Jakarta: Balai Pustaka.

Remilia. 2016. Masyarakat Desa Berpendidikan Rendah. Skripsi. Bengkulu: Universitas Bengkulu.

Samiyah. 2014. Relevansi Tujuan Pendidikan Nasional Dengan Tujuan Pendidikan Islam (Telaah Atas UU No. 20 Tahun 2003. Http://library.walisongo.ac.id/digilib/file/disk1/14/jtptiain-gdl-sl-2001samiyah319-bab1_319-6.pdf. (Diakses 3 Agustus 2018). 
19 I Rahmawati Talopo, Hasan Pribadi, Asep Topan

Disfungsi Keluarga Dalam Pendidikan Formal Anak

Silalahi, Ulber. 2010. Metode Penelitian Sosial. Bandung: Refika Aditama.

Siswanto. 2007. Kesehatan Mental (Konsep, Cakupan dan Perkembangannya). Yogyakarta: C.V. Andi.

Soekanto, Soerjono. 2009. Sosiologi Keluarga Tentang Ikhwal Keluarga, Remaja, dan Anak. Jakarta: Rineka Cipta.

Soekanto, Soerjono. 2010. Sosiologi Suatu Pengantar. Jakarta: Rajawali Persada.

Soetjiningsih. 2004. Tumbuh Kembang Remaja dan Permasalahannya. Jakarta: Rhineka Cipta.

Suardi, Moh. 2002. Pengantar Pendidikan Teori dan Aplikasi. Jakarta: Indeks.

Sugiyono. 2005. Metode Penelitian Pendidikan, Kuantitatif, Kualitatif, R\&D. Bandung: Afabeta.

Sugiyono. 2008. Metode Penelitian Pendidikan, Kuantitatif, Kualitatif, R\&D. Bandung: Alfabeta.

Sugiyono. 2010. Metode Penelitian Kualitatif dan Kuantitatif, R\&D. Bandung: Alfabeta.

Umar, Tirtarahardja. 2008. Pengantar Pendidikan. Jakarta: Rineka Cipta.

Yusuf, Soelaiman. 2004. Konsep Dasar Pendidikan. Jakarta: Rineka Cipta 
